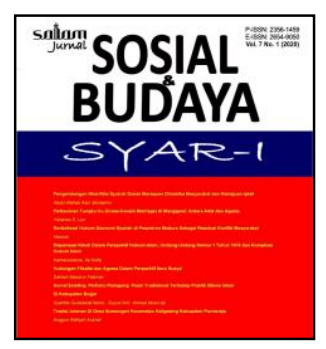

P-ISSN: 2356-1459. E-ISSN: 2654-9050

Vol. 8 No. 2 (2021), pp. 459-468

DOI: $10.15408 /$ sjsbs.v8i2.19868

http://journal.uinjkt.ac.id/index.php/salam/index

\title{
Zafry Zamzam, Pandangan Kebangsaan Antara Unitarisme Atau Federalisme Untuk Tatanan Kenegaraan Republik Indonesia*
}

\author{
Fazakkir Zamzam, ${ }^{1}$ Siti Frosidha Hez, ${ }^{2}$ Faizatunniza, ${ }^{3}$ Fakhry Zamzam, ${ }^{4}$ \\ Kejati Sumsel, Sekwan OKI, FKM Universitas Indonesia, MM UIGM Palembang \\ do) \\ 10.15408/sjsbs.v8i2.19868
}

\begin{abstract}
This research is aimed at reexamining the big ideas of the national warrior from Kalimantan, Zafry Zamzam, who has always been persistent in choosing Unitarism as the state administration of the Republic of Indonesia which he initiated since the Dutch and Japanese colonial times, to the beginning of independence in 1945. The hope is that he can refresh about who and how he did. This study used a qualitative approach, namely biogafi research conducted through library research and interviews with informants. Sources of data are taken from documentation, pages on the internet and informants from the Zafry Zamzam family. Zafry Zamzam, a religious national fighter from Kalimantan, is known as a multitalented figure; He has played many roles, starting as a Koran teacher in Surau, a People's School teacher, a journalist, a writer, a politician, a bureaucrat to an academician. In this research, in addition to exploring his views during the struggle which are still relevant to the current problem of national unity facing the Indonesian nation today. His view is that the constitutional form of the Republic of Indonesia which is in line with the spirit of the struggle for independence of the Indonesian nation is Unitarism in the form of a unitary republic of Indonesia, rather than choosing a federalist government system that divides power to the federal state.
\end{abstract}

Keywords: Zafry Zamzam, State Administration, Unitarism and Federalism

\begin{abstract}
Abstrak
Penelitian ini ditujukan untuk menggali kembali gagasan besar pejuang nasional asal Kalimantan Zafry Zamzam, selalu gigih memilih Unitarisme sebagai ketatanegaraan Negara Republik Indonesia yang digagasnya sejak masa penjajah Belanda dan Jepang, hingga awal kemerdekaan 1945. Harapannya dapat menyegarkan kembali tentang siapa dan bagaimana sepak terjangnya. Penelitian ini menggunakan pendekatan kualitatif, yaitu penelitian biografi yang dilakukan melalui library reseach dan wawancara kepada informan. Sumber data diambil dari dokumentasi, laman pada internet dan informan dari keluarga Zafry Zamzam. Zafry Zamzam, pejuang nasional agamis asal Kalimantan, dikenal sebagai sosok multitalenta; banyak peran dilakoninya mulai sebagai guru ngaji di surau, guru Sekolah Rakyat, jurnalis, sastrawan, politisi, birokrat hingga akademisi. Dalam penelitian ini disamping untuk menggali kembali tentang pandangannya selama
\end{abstract}

\footnotetext{
* Received: January 25, 2021, Revision: January 30, 2021, Published: April 1, 2021.

${ }^{1}$ Fazakkir Zamzam is Kajati Sumsel. Email: zamzam.kejaksaan@gmail.com

2 Siti Frosidha Hez is Setwan OKI. Email: risnazamzam2@gmail.com

${ }^{3}$ Faizatunnisa is FKM Universitas Indonesia. Email: faizatunnisazam@yahoo.com

${ }^{4}$ Fakhry Zamzam is Magister Manajemen UIGM Palembang. Email: fakhry@uigm.ac.id
} 
perjuangan yang masih relevan dengan persoalan kesatuan bangsa yang sedang dihadapi bangsa Indonesia saat kini. Pandangannya bahwa bentuk ketatanegaraan Negara Republik Indonesia yang sejalan semangat perjuangan kemerdekaan bangsa Indonesia adalah Unitarisme dalam bentuk negara kesatuan republik Indonesia, daripada memilih sistem pemerintah federalisme yang membagi kekuasaan kepada negara federal.

Kata Kunci: Zafry Zamzam, Tata Negara, Unitarisme dan Federalisme

\section{A. PENDAHULUAN}

Seorang Zafry Zamzam, pejuang kemerdekaan Republik Indonesia asal Kalimantan sudah semakin terlupakan dan belum banyak dikenal generasi milenial sekarang ini. Beliau memilih perjuangan kemerdekaan tidak menggunakan senjata, lebih intensif menggunakan coretan penanya yang tajam serta gerakan politik, sehingga mampu menggetarkan para penjajah pada waktu itu. Semasa hayatnya Zafry Zamzam, juga dikenal sebagai legislator sebagai anggota MPRS, jurnalis pendiri dan ketua PWI Kring Banjarmasim pertama, sebagai Birokrasi pernah menjabat Kepala Djawatan Penerangan Provinsi Kalimantan Selatan, puncak kariernya menjadi akademisi ketika diangkat sebagai Rektor IAIN Antasari hingga wafat 1972. Beliau bisa dikatakan ulama multitalenta dan sebagai ulama yang berwawasan luas. Selain itu beliau juga intelektual yang cerdas, aktivis yang idealis, pejuang yang sangat berani, jurnalis yang kritis, birokrat yang sederhana dan muballig yang pantang menyerah.

Mujiburrahman (2018) cerita hidup Zafry Zamzam adalah pergumulan Islam, modernitas dan kebangsaan yang terjadi di Kalimantan Selatan. ${ }^{5}$ Zafry Zamzam adalah orang yang paling berani menentang gagasan negara Islam pada kisaran tahun 1950, ia tetap kukuh menginginkan Pancasila. Dia ingin Islam itu modern, Islam itu maju dan pada saat yang sama Islam adalah bagian dari Indonesia. Pejuang selalu konsistensi mempertahankan pandangan tentang Negara kesatuan Republik Indonesia, dipegang teguh sejak perjuangan melawan penjajah Belanda hingga awal kemerdekaan Republik Indonesia.

Pandangannya tentang kebangsaan dan ketatanegaraan yang digagas sebelum kemerdekaan Republik Indonesia, sangat menarik dikaji kembali secara lebih mendalam, sehingga mendapatkan nilai-nilai untuk dapat diwariskan bagi generasi milenial Bangsa Indonesia yang sedang menghadapi diskusi panjang persoalan Negara Kesatuan Republik Indonesia.

\section{B. KAJIAN PUSTAKA}

Penggunaan diterminant unitarisme dalam sistem ketatanegaraan saat ini sudah jarang terdengar, Strong (2011) melihatnya unitarisme sebagai konsepsi negara kesatuan yang memahami unitarisme adalah struktur negara di mana kekuasaan

${ }^{5}$ Mujiburrahman, Bedah Buku Zafry Zamzam,

https://banjarmasin.tribunnews.com/2018/12/04/bedah-buku-mengenai-zafry-zamzam-pakar-sejarahinginkan-ini, diakses 20 Desember 2020. 
dan wewenang legislatif tertingginya berada pada pemerintah pusat. ${ }^{6}$ Negara kesatuan sering juga dikenal sebagai negara tunggal monosentris. Dalam negara kesatuan hanya mengenal satu pemerintahan, satu kepala negara yang berlaku bagi seluruh wilayah negara. Hakikat negara kesatuan yang sesungguhnya adalah kedaulatan tidak terbagi-bagi baik ke luar maupun ke dalam dan kekuasaan pemerintah pusat tidak dibatasi. Strong (2011), menggambarkan negara kesatuan adalah bentuk negara yang wewenang legislatif tertinggi dipusatkan dalam suatu badan legislatif nasional. Kekuasaan negara dipegang oleh pemerintah pusat. Pemerintah pusat dapat menyerahkan sebagian kekuasaannya kepada daerah berdasarkan hak otonomi, tetapi pada tahap terakhir kekuasaan tetap berada di tangan pemerintah pusat.

Selanjutnya pemikiran Strong (2011) memaknai negara kesatuan adalah negara bersusunan tunggal, yakni kekuasaan untuk mengatur seluruh daerahnya ada di tangan pemerintah pusat. Pemerintah pusat memegang kedaulatan sepenuhnya, baik ke dalam maupun ke luar. Hubungan antara pemerintah pusat dengan rakyat dan daerahnya dapat dijalankan secara langsung. Dalam negara kesatuan hanya ada satu konstitusi, satu kepala negara, dan satu parlemen. Demikian pula penyelenggaraan pemerintahan, pemerintah pusat memegang wewenang tertinggi dalam segala aspek pemerintahan. Negara kesatuan mempunyai dua sistem, yaitu sentralisasi dan desentralisasi. Dalam negara kesatuan bersistem sentralisasi, semua hal diatur dan diurus oleh pemerintah pusat, sedangkan daerah hanya menjalankan perintah-perintah dan peraturan-peraturan dari pemerintah pusat.

Mengenai federalisme dipahami sebagai konsepsi ketatanegaraan di mana kekuasaan memerintah dibagi antara pemerintah pusat dan negara bagian yang sering disebut federasi. Federalisme memungkinkan otonomi lokal yang memadai, dalam arti memiliki otoritas di wilayah atau teritori tertentu, dan politik di dalam teritori tersebut terbebas dari campur tangan kekuatan yang berasal dari luar teritori. Federalisme sebagai sebuah konsep politik di mana sekelompok anggota terikat kepala perwakilan pemerintahan. Penggunaan istilah federalisme banyak digunakan menggambarkan sistem pemerintahan di mana kedaulatan secara konstitusional dipisahkan antara pemerintah pusat dan pemerintahan unit politik konstituen seperti negara bagian. Federalisme adalah sistem berdasarkan aturan demokratis dan lembaga-lembaga di mana kekuasaan memerintah dibagi antara pemerintah pusat dan pemerintah provinsi/negara bagian, menciptakan apa yang sering disebut federasi. Strong (2011) berpendapat bahwa sifat utama atau dasar negara federal adalah adanya pembagian kekuasaan antara pemerintah federal dengan unit-unit federasi. Pembagian kekuasaan dalam negara federal (the federal authority) dapat dilakukan dengan dua cara, tergantung dimana diletakkan sisa atau residu atau kekuasaan simpanan (reserve of powers).

Maka dalam konteks ini, pandangan Zafry Zamzam tentang unitarisme sebagai jaminan dapat berdiri tegaknya Negara kesatuan Republik masih sangat

\footnotetext{
${ }^{6}$ C.F Strong, 2011, Konstitusi-Konstitusi Politik Modern, Terjemahan, Bandung Penerbit Nusa Media.
} 
relevan dengan pemerintahan sekarang, sedangkan paham federasi yang sempat diterapkan dalam Republik Indonesia sebagai alat untuk memecah negara kesatuan, terbukti hanya bisa berjalan sekitar satu tahun dan tentu saja tidak cocok bagi negara bercorak kepulauan seperti Indonesia.

\section{METODE PENELITIAN}

Metode yang digunakan dalam penelitian ini menggunakan metode pendekatan normatif yuridis yang dilakukan dengan cara menelaah dan menginterpretasikan hal-hal yang bersifat teoritis menyangkut asas, konsepsi, doktrin, dan norma hukum yang berkaitan dengan pandangan kebangsaan Zafry Zamzam. Jenis penelitian yang digunakan adalah penelitian kualitatif. Penulis menggunakan pendekatan undang-undang (statue approach) dan pendekatan konseptual (conceptual approach).

\section{HASIL TEMUAN DAN PEMBAHASAN}

Yulisliani Noor (2018), sejarahwan dari Universitas Lambung Mangkurat. Melihat perjalanan perjungan kemerdekaaan Zafry Zamzam, menebarkan semangat anti kolonial dan menuntut kemerdekaan Republik Indonesia. Sehingga layak menjadi Pahlawan Nasional karena bagian dari perang perjuangan fisik bahkan dalam jajaran Gubernur pertahanan Kalimantan. Dalam sejarah ia juga sebagai anggota Dewan Banjar yang gigih di dalam memperjuangkan Republik Indonesia. ${ }^{7}$ Ia juga tokoh pejuang yang turut memberitakan kemerdekaan dan menderangar RI merdeka dari Belanda. Majalah Republik yang berupa Stensilan terbit pada 17 Agustus 1946 di Kandangan untuk mengimbangi Soeara Kalimantan, harian kooperatif terhadap Belanda. Majalah ini menjadi media perjuangan pertama di Kalimantan Selatan dengan pemimpin umum sekaligus pemimpin redaksinya Zafry Zamzam. Terbitan pertama Republik memuat lengkap susunan kabinet pertama dan kabinet Sutan Sjahrir serta teks Proklamasi dalam bahasa Indonesia dan Inggris.

Abdurrachman menurut Ikhsanudin (2015), melihat majalah Republik yang dikelola Zafry Zamzam, kuat sekali memperjuangkan agar supaya Kalimantan Selatan tetap merupakan wilayah Republik Indonesia dan menentang dengan tegas politik separatisme Belanda yang dilancarkan melalui konferensi-konferensi Malino dan Denpasar untuk mendirikan negara Kalimantan.

Pandangan Wajidi (2012), sejak tahun 1948, Zafry Zamzam terpilih menjadi anggota Dewan Banjar dan aktif menggerakkan dewan tersebut untuk kepentingan perjuangan kemerdekaan. ${ }^{8}$ Sebagai anggota Dewan Banjar, Zafry Zamzam punya

\footnotetext{
${ }^{7}$ Yulisliani Noor. Bedah Buku Zafry Zamzam, “https://banjarmasin.tribunnews.com/2018/12/04/bedah-buku-mengenai-zafry-zamzam-pakar-sejarahinginkan-ini, di akses 20 Desember 2020.

${ }^{8}$ Arief Ikhsanudin, Pers Perjuangan di Kalimantan, 11 Agtustus 2015

https://historia.id/politik/articles/pers-perjuangan-di-kalimantan-PMLnI, di akses 20 Desember 2020
} 
pendirian tegas. Ia menolak usulan pembubaran Dewan Banjar yang disuarakan petinggi ALRI Divisi IV Pertahanan Kalimantan. Zafry Zamzam menyatakan tidak setuju dengan usul pembubaran Dewan tersebut, dengan alasan tanpa Dewan Banjar di daerah ini tidak akan ada pengakuan pemerintahan sendiri yang sah dari Belanda. Apabila Dewan Banjar dibubarkan, maka Belanda dapat bertindak dengan bebas di daerah ini. Karena itu menurut Zafry Zamzam dari pada dibubarkan lebih baik Dewan Banjar memastikan diri sebagai Dewan Perwakilan Rakyat Pemerintahan ALRI Divisi IV Kalimantan, dan ALRI Divisi IV supaya merebut kantor-kantor pemerintahan Belanda. Selain berjuang di bidang politik, Zafry Zamzam juga menggunakan media massa sebagai sarana perjuangan. Pada tahun 1946, Zafry Zamzam menerbitkan majalah Republik di Kandangan. Majalah ini secara sengaja melakukan penerbitan perdananya bertepatan dengan hari ulang tahun yang kemerdekaan Republik Indonesia pertama.

\section{Gelora Semangat Kebangsaan}

Sejak muda sekali, ketika usia baru beranjak 13 tahun, Zafry Zamzam dapat dikatakan sangat milenial pada waktu itu, sudah terlibat dalam penggalangan kesatuan bangsa. Tuntutan keadaan membentuk anak muda Zafry Zamzam lebih cepat matang dari usianya terpanggil untuk berjuang. Mungkin tidak dapat dibandingan dengan kondisi sekarang anak pada usia 13 tahun dan baru lulusan sekolah dasar sudah terlibat memikirkan persoalan bangsa. Dimulai mengikuti pergerakan nasioal yang bernaung pada ormas non kooperartif Musyarawaratut Tholibin Kandangan tahun 1931. Disini tempat berkumpulnya pemuda terpelajar yang memperjuangkan kesatuan bangsa melalui musyawarah.

Gelora semangat kebangsaan tetap bertahan ketika menjadi Guru Sekolah Rakyat di Alabio tahun 1937, Kenkarikan Alabio pernah mengultimatumnya agar tidak mengajarkan Lagu Indoneia Raya dengan muridnya tidak pula diindahkannya. Bahkan tidak bergiming ketika diimingi jabatan kepala sekolah, jawabannya sangat tegas dan memilih berhenti sebagai guru daripada menukar semangat perjuangan kebangsaannya. Pada waktu itu jabatan kepala sekolah merupakan jabatan sangat terhormat dengan penghasilan sangat tinggi, Zafry Zamzam tidak tergiur ketika ditukar dengan paham kebangsaannya

Penerima tanda jasa kehormatan Bintang Jasa Utama dari Pemerintah Republik Indonesia tahun 2012 ini. Seorang nasionalis agamis, Zafry Zamzam berseberangan pemikiran dengan Idolanya Bung Karno, tidak sepaham dengan gagasan Nasakom. Agama yang diyakininya percaya kepada Tuhan YME, tidaklah mungkin bersatu dengan komunisme yang jelas atheis. Sehingga dengan ikhlas memilih mengajukan pengundurkan diri dari penyambung lidah rakyat sebagai Kepala Djawatan Penerangan Provinsi Kalimantan Selatan tahun 1964.

Selain berjuang di bidang politik, Zafry Zamzam juga menggunakan media massa sebagai sarana perjuangan. Pada tahun 1946, Zafry Zamzam menerbitkan majalah Republik di Kandangan. Majalah sengaja melakukan penerbitan perdananya bertepatan ulang tahun pertama kemerdekaan Republik Indonesia. Edisi perdana 
majalah Republik menggugah dan mengingatkan Proklamasi Kemerdekaan telah berkumandang setahun lalu. Republik memuat kembali secara lengkap teks Proklamasi Kemerdekaan 17 Agustus 1945 dan susunan kabinet Republik Indonesia pertama. Republik secara berani memuat artikel yang menyerang tokoh-tokoh yang memihak Belanda, seperti yang ditulis oleh Isah (nama samaran Zafry Zamzam) yang menyerang Abdurrahman Sidik tokoh partai Serikat Rakyat Islam (SRI) seorang Republiken pimpinan Partai Serikat Muslim Indonesia (SERMI), kemudian memihak penjajah. Sementara Pemimpin Redaksi Majalah Republik ini dikenal sebagai tokoh Partai Serikat Kerakyatan Indonesia (SKI), sebuah partai Republiken yang menentang ide federalisme. Karena aktivitasnya itulah, maka ia bersama rekan-rekannya berulang kali ditangkap Belanda.

Perjuangan Zafry Zamzam dalam memertahankan kemerdekaan Republik Indonesia jauh lebih berat, dibandingkan penjuangan mendapatkan kemerdekaan. Ironisnya justeru setelah kemerdekaan Zafry Zamzam, sebanyak tiga kali meringkuk dinginnya penjara sebagai tahanan politik.

\section{Konsisten Dengan Unitarisme.}

Bentuk ketatanegaraan yang dipahami Zafry Zamzam, menjadi pandangannya sejak masa perjuangan hingga kemerdekaan tidak pernah berubah adalah Unitarisme. Indonsia sebagai negara kepulauan yang terdiri dari beberapa suku bangsa unitarisme adalah pilihan yang sesuai dengan kearifan lokal. Negara kesatuan Republik Indonesia merupakan pilihan, dengan konsekwensi menerima kelemahan dalam sistem unitarisme. Ketika Belanda dengan sekutunya datang kembali ke Indonesia setelah kemedekaan, menawarkan federasi sebagai bentuk Negara Indonesia, sebagai politisi melihat sebagai alat memecah kesatuan bangsa Indonesia. Pengalaman lapangan yang merasakan langsung debu-debu revolusi, sangat paham dengan politik Divide Et Empera Belanda, dengan federasi ditujukan agar terjadi pergolakan besar di daerah untuk memisahan dari Republik Indonesia. Sehingga nantinya akan menjadi entry point imprialisme menjajah kembali Indonesia.

Perjuangan unitarisme disalurkannya melalui partai Syarikat Kebangsan Indonesia (SKI), pada waktu partai ini dikenal pro unitarisme. Perjuangan berlanjut jalur parlemen, Zafry Zamam selalu gigih dengan ide-ide unitarisme yang sentralistik daripada federalisme gagasan Belanda untuk pembentukan negara Kalimantan. Seperti dituturkan Rifah $\mathrm{Hb}$ (2015), sewaktu hangatnya wacana antara Federasi atau unitarisme, Zafry Zamzam lebih cenderung unitarisme. Menyadari tidak ada sistem yang sempurna, unitarisme dengan segala kelemahannya masih paling tepat dengan kondisi bangsa Indonesia.

Ikhsanudin (2015) gerakan para pendukung kemerdekaan Indonesia mendirikan media massa ditujukan untuk mengimbangi media massa pro-Belanda. Selaku anggota PBI, Zafry Zamzam aktif mempropagandakan paham kebangsaan yang menjadi asas PBI kepada masyarakat semasa perjuangan kemerdekaan. Zafry Zamzam menuangkan pemikirannya dalam majalah Majalah Bingkisan, berisi kritikan terhadap Pemerintah Hindia Belanda. Karena kegiatan politiknya di PBI dan 
tulisan-tulisannya itulah, maka Zafry Zamzam dipanggil Asisten Kiai di Alabio dan kemudian dipanggil Kontrolir Amuntai untuk diminta pertanggungjawaban atas kegiatannya yang bersifat politik di PBI.

Indonesia memproklamasikan kemerdekaan pada 17 Agustus 1945, Belanda mencoba datang lagi lndonesia untuk menjajah, RIS dibentuk sebagai wujud kesepakatan antara Indonesia, Belanda, dan Bijeenkomst voor Federal Overleg pada Konferensi Meja Bundar (KMB). Konferensi meja Bundar di Denhaag 23 agustus 1949, sebagai tindak lanjut perjanjian roem Royen. Setelah melalui perundingan cukup lama menghasilkan putusan: (1). Belanda menyerahkan kedaulatan atas Indonesia sepenuhnya kepada Republik Indonesia Serikat dengan tidak bersyarat lagi dan tidak dapat dicabut dan karena itu mengakui Republik Indonesia Serikat sebagai Negara yang merdeka dan berdaulat. (2). Republik Indonesia Serikat menerima kedaulatan itu. (3). Kedaulatan akan diserahkan selambat-lambatnya pada tanggal 30 Desember 1949.

Pemerintah Belanda menyerahkan kedaulatan kepada Republik Indonesia Serikat pada 27 Desember 1949. Sejak itu menandai lahirlah negara Republik Indonesia Serikat (RIS) yang meliputi dari Republik Indonesia dan Negara Negara Bagian. Sukarno sebagai Presiden dan Mohammad Hatta sebagai Perdana Menteri yang memimpin sebuah Republik federasi berdaulat yang terdiri dari 16 negara bagian. Sedangkan yang menjalankan tugas sebagai Presiden RI ditunjuklah Mr.Assat. Tak lama setelah terbentuknya RIS, mulailah muncul gejolak di daerah menuntut agar kembali menjadi negara kesatuan atau Unitarisme seperti digagas Zafry Zamzam. Setelah melalui proses yang mendebarkan maka pada tanggal 17 Agustus 1950, RIS dinyatakan bubar dan kita kembali menjadi negara kesatuan Republik Indonesia dan menggunakan Undang Undang Dasar Sementara 1950.

Rirnadi, 2010, melihat perkembangan masalah ketatanegaraan Indonesia masa revolusi sangat erat kaitannya dengan kehadiran kekuatan asing. Indonesia mengalami perubahan bentuk negara dari kesatuan menjadi negara federal bukan saja disebabkan oleh faktor dalam negeri, tetapi ada hubungannya dengan kehadiran Belanda dan Australia. Republik Indonesia Serikat, (RIS), adalah negara federasi yang berdiri pada tanggal 27 Desember 1949 sebagai hasil kesepakatan tiga pihak dalam Konferensi Meja Bundar: Republik Indonesia, Bijeenkomst voor Federaal Overleg (BFO), dan Belanda. Kesepakatan ini disaksikan juga oleh United Nations Commission for Indonesia (UNCI) sebagai perwakilan Persatuan Bangsa Bangsa. Belanda mengakui kemerdekaan Indonesia pada 27 Desember 1949, selang empat tahun setelah proklamasi kemerdekaan RI pada 17 Agustus 1945.

Daerah Banjar wilayah Banua lima Kalimantan Selatan konsisten bergabung dalam wilayah otonom dan tak tergabung dalam federasi, bersama dengan (1). Jawa Tengah (2). Kalimantan Barat (Daerah Istimewa), (3). Dayak Besar, (5) Kalimantan Tenggara (6) Kalimantan Timur (tidak temasuk bekas wilayah Kesultanan Pasir) (7). Bangka (8). Belitung dan (9) Riau. Ternyata pembentukan Republik Indonesia Serikat, yang menjadi prasyarat penyerahan kedaulatan Belanda kepada republik Indnesia tidak berlangsung langsung, 17 Agustus tahun 1950, kembali Kepada Negera kesatuan Indonesia. Setelah berakhirnya pemerintahan RIS pada 1950, Pemerintahan 
Republik Indonesia masih melanjutkan model demokrasi parlementer yang liberal. Kabinet dipimpin oleh seorang perdana menteri dan bertanggung jawab kepada parlemen.

Pemahaman sistem pemerintahan unitarisme semakin relevan setelah RIS dibubarkan, tetap berdiri kokoh hingga sekarang dengan menyesuaikan tuntutan zamannya, Konsep Negara Kesatuan Republik Indonesia sekarang sedang diuji, oleh berbagai elemen bangsa yang katanya memertahankan negara Kesatuan Repulik Indonesia

\section{Warisan Nilai-Nilai Kebangsaan Indonesia}

Zafry Zamzam memang telah wafat 23 Desember 1972; namun nilai-nilai kebangsaan dan kejuangannya masih berkembang hingga sekarang. Beberapa nilai luhur yang dapat diwariskan kepada generasi milineal sekarang menurut Zamzam (2014) seperti berikut;

(1) Teguhlah pertahankan pendirian, konsisten dengan prinsif yang diyakininya, tidak akan menukar dengan suatu apapun, sanggup menanggung risiko sekalipun pahit;

(2) Lebih mendahulukan kepentingan yang lebih luas, daripada kepentingan kelompok apalagi untuk kepentingan pribadi;

(3) Semangat kejuangan tak lekang kena panas dan tak akan lapuk oleh hujan, antisipasi berbagai tantangan yang akan dihadapi;

(4) Hidup merdeka lebih mulia daripada dijajah, memilih mati masuk surga daripada hidup dalam penjajahan;

(5) Komitmen menjaga gelora semangat kebangsaan, bagaikan api nan tak kunjung padam takan berhenti sampai tujuan didapat.

\section{E. KESIMPULAN}

Zafry Zamzam, pejuang Kalimantan lebih menggunakan kekuatan goresan penanya dan kekuatan politik daripada menggunakan senjata dalam menuju Kebangsaan Indonesia Merdeka Semangat kebangsaan Negara Kesatuan Republik Indonesia yang telah digagas Zafry Zamzam sejak masa perjuangan kemerdekaan, kemedekaan Indonesia dan sampai sekarang masih relevan dengan kondisi kebangsaan. Begitu juga gagasan unitarisme yang diperjuangkannya sejak merebut kemerdekaan telah sejalan tata pemerintahan Republik Indoensia Sekarang yang berkembang mengikuti tuntutan zaman, semoga! 


\section{REFERENSI}

Arief Ikhsanudin, 2015, Pers Perjuangan di Kalimantan, 11 Agtustus 2015 https://historia.id/politik/articles/pers-perjuangan-di-kalimantan-PMLnI

C.F Strong, 2011, Konstitusi-Konstitusi Politik Modern, Terjemahan, Bandung Penerbit Nusa Media

Eka Pertiwi, 2018, Bedah Buku Mengenai Zafry Zamzam, banjarmasinpost.co.id,

Fakhry Zamzam, 2015, Zafry Zamzam, Waja Hampai Kaputing, Yogyakarta, Penerbit Deepublish.

Haryono, Rinardi, 2010, Dari Negara Federal Menjadi Negara Kesatuan (Proses Perubahan Negara Republik Indonesia Serikat Menjadi Negara Kesatuan Republik Indonesia). Jurnal Citra Leka dan Sabda .

Mujiburrahman. 2018 https://banjarmasin.tribunnews.com/2018/12/04/bedah-bukumengenai-zafry-zamzam-pakar-sejarah-inginkan-ini

Wajidi. 2012 MARET 16, 2012

Yulisliani Noor. 2018. https://banjarmasin.tribunnews.com/2018/12/04/bedah-bukumengenai-zafry-zamzam-pakar-sejarah-inginkan-ini. 
Fazakkir Zamzam, Siti Frosidha Hez, Faizatunniza, Fakhry Zamzam

468 -Fakultas Syariah dan Hukum UIN Syarif Hidayatullah Jakarta 